\title{
Finding the 'tipping point': A Framework for building an institutional learning community to improve learning and teaching
}

\author{
Deborah West \\ Charles Darwin University, Australia \\ deborah.west@cdu.edu.au
}

Keywords: learning community, scholarship of teaching and learning, institutional framework, SoTL

\begin{abstract}
Universities are inherently learning communities in the broadest sense. Central to this and generally explicit in university mission statements are their goals in providing quality experiences for students. The scholarship of teaching and learning (SoTL) is a core element in the ongoing improvement of the student experience which embodies a valued scholarly research process. The idea of building an institution wide learning community with a focus on SoTL should therefore be at the heart of the university's agenda and a relatively easy undertaking. Yet for a range of reasons it proves elusive in many institutions. This paper explores the underlying issues surrounding this challenge and identifies a range of factors which lay the foundation for building a SoTL learning community. It begins with an examination of the key concepts of SoTL, learning communities and structuralism to set the scene. The paper then examines key literature and existing data on SoTL and concludes with the presentation of a framework for building an institution wide learning community which supports the improvement of learning and teaching for students using a SoTL approach.
\end{abstract}

\section{What is the scholarship of teaching and learning and why is it important?}

The scholarship of teaching and learning (SoTL) refers to a systematic approach to reflecting on teaching practice to improve outcomes for students. There are many definitions and approaches to SoTL within the literature but the work of Boyer (1990) in relation to scholarship laid a solid foundation for further development. Boyer outlined four key elements of scholarship: discovery, integration, application and teaching. The language and approach used within SoTL approaches is akin to the research process. For example discovery, refers to the contribution of knowledge; integration to drawing on existing knowledge to develop new insights; application to being able to apply this and teaching to being able to extend knowledge through sharing (Williams, Goulding \& Seddon, 2013). As Hutchings, Borin, Keesing-Styles, Martin, Michael, Scharff, Simkins and Ismail (2013) point out:

In this, and in many definitions of SoTL generated in the years that followed, the emphasis was on intellectual work, on learning and teaching as areas for systematic study, and on a process of knowledge building. (p. 37)

SoTL is therefore the scholarly approach applied to learning and teaching. It is not generally pure research but rather the application of research to learning and teaching with the intention being the improvement of teaching and learning and subsequently the student experience. 
Typically, SoTL has a strong focus on the actions of the teacher, and their critical self-reflection of this, in attempting to help and improve student learning. Having a clear SoTL culture and approach is central to 'improving the ability of institutions to support student learning' (Martensson, Roxa \& Olsson, 2011 in Williams, Verwoord et al, 2013, p. 50). It is foundational in this respect as it provides a clear framework for the development of an evidence base about how to improve learning and teaching including the links to student outcomes. While this is inherently what universities should be seeking to do, it is also an essential requirement in the current era of accountability and outcomes driven funding (Williams, Verwoord, et al, 2013). Yet as Williams, Verwood et al. (2013) point out, such a dialogue is unlikely to inspire academics to engage in this process. Rather it is the link to their identity as scholars, a drive to be the best possible teacher and links to careers which are central. However, these themes can converge to some extent as accountability might be a driver for structural change within institutions which can support the development of a SoTL cultures and the focus on the scholarly identity. With this brief overview of SoTL, we now turn to how learning communities might be useful to developing a SoTL culture.

\section{Learning Communities}

The term learning community is used in a range of contexts to mean a variety of things; many of which are vague and unhelpful (DuFour, 2004). Therefore it is essential to unpack and define our understanding and focus. To start we look at the concept of community. Plant (1974) in his seminal work on community development highlighted the key components of a community through a comparison with a group. He argued that a community is a relatively stable and permanent structure which is pluralistic and heterogeneous while a group is more specialised, transitory and relatively homogeneous. Quite obviously these operate on a continuum but it is the more lasting end of the spectrum - that is a community - something that is enduring, has a permanent structure and spans and engages the heterogeneous institutional population that we seek to develop.

Additionally, the work of Lave and Wenger (1991) and Wenger (1999; 2006) on communities of practice provides further parameters. Wenger $(2006$, p. 1) defines communities of practice as "...groups of people who share a common concern or a passion for something they do and who interact regularly to learn how to do it better". He also suggests that there are three critical characteristics which need to be present: the domain, the community and the practice. Essentially, the domain provides a shared focus, community the relationships and activities around that focus and practice is about building and sharing resources, knowledge, tools etc. It is the combination of these three elements that leads to a group becoming or being defined as a community of practice. While slightly at odds with Plant in relation to the key concept of communities, the work of Wenger highlights the role of learning.

DuFour (2004) poses some interesting questions in relation to learning communities which are useful in assisting to define what it is we seek. While obviously focused on the school context, these questions still remain useful:

What are the "big ideas" that represent the core principals of professional learning communities?

How do these principles guide schools' efforts to sustain the professional learning community model until it becomes deeply embedded in the culture of the school? (p.1)

The 'big idea' in our endeavour is to have an institutional focus on SoTL providing an environment which supports, encourages and values the SoTL approach. Rather than the 
broader learning community which a university arguably is on a number of levels; we seek to have an explicit learning community which develops and guides SoTL endeavours. The next question is how this principle informs efforts by a university to embed a SoTL culture across the institution; that is a SoTL learning community.

Community development frameworks and structuralism tell us that we need to deal with the underlying conditions and structures that support such an approach. This is reinforced by the work of Williams, Veerwood, Dalton, McKinnnon, Strickland, Pace and Pool who argue that ... "understanding the structure of the organisation one is trying to influence is essential for developing strategies to increase the value of SoTL work in a culture" $(2013$, p. 54). It is at this point that a sociological perspective is useful.

\section{Structuralism}

From a sociological perspective the concepts of structure, social constructivism, culture and agency all play a role in building a fertile environment for a learning community focusing on SoTL. A structuralist perspective indicates that "... human action should be understood as a product of an underlying social structure (or social system) ..." (Van Krieken, Habibis, Smith, Hutchins, Martin \& Maton, 2010, p. 5). In this context the institution itself and the broader tertiary sector have some elements that shape those who work within them and the relative value placed on such elements. Structural elements can therefore either support or hinder certain activities; in our context, the development of a SoTL learning community. It is from this perspective that this paper examines the underlying elements that are required to support SoTL development.

However, such structures are shaped by human behaviour and interactions and change over time - that is they are socially constructed and humans can act upon them (agency). As such, a learning community and the development of a SoTL culture can be influenced. In that sense, we can look for the lessons and take action to pursue this goal in a systematic way. It is said that there is a 'tipping point' in cultural change and it is this point that we seek to find.

Language is seen to be central to social construction - a point that we will return to in relation to the concept of SoTL and its relative place in institutions. Language is also central to the concept of culture and the shared understandings that are developed within an organisation. This suggests that as we seek to build a culture of SoTL, which underpins the learning community, attention must be paid to the language that is used and the ways in which the community views such language.

In order to consider how the above ideas from sociology as well as learning communities and SoTL come together in institutions we turn to two sources: the existing literature on developing an institutional culture of SoTL and an analysis of some existing data on nationally recognised expressions of SoTL.

\section{Key elements for building a SoTL community}

\section{The literature}

A range of factors have been identified as supporting a SoTL culture throughout the literature. First and foremost having institutional support at every level is essential to improve learning and teaching (Major \& Palmer, 2006; Brew, 2012; Williams, Goulding and Seddon, 2013; Williams, Verwoord et al, 2013). Williams, Verwoord et al. (2013, p. 49) go further to imply a 
clear strategy that 'coordinates the actions of individuals' within, across and between schools, faculties and central services. Their work is particularly focused on the development of learning communities and suggests that it is not enough to simply have the elements in place but that it needs to be actively supported, coordinated and acted upon.

Related to this institutional support is the clear valuing of SoTL. While it is common for universities to indicate that they value learning and teaching, they must go further to value the scholarly approach to improving this endeavour via outward and visible signs of such support. In a National Centre for Vocational Education Research (NCVER) study Williams, Goulding and Seddon (2013)

\begin{abstract}
... observed that the scholarship of teaching and learning is regarded as a second discipline in higher education and is not recognised as equivalent to discipline based scholarship, is not necessarily part of core practice and is not highly valued. This was attributed to the structures for research assessment forcing the separation of teaching from disciplinary research and muting the work of the scholarship of teaching and learning. (p. 29)
\end{abstract}

Both teaching and learning and research are critical elements of a university's core business, prestige and funding. Clearly there are some external drivers which lead to mixed messages about the value of teaching and learning vis a vis research. However, the key argument for supporting SoTL is that it improves the learning experience of students which is linked to retention and student satisfaction (as evidenced by the work of Brew, 2012) and a critical part of university funding. Measures such as retention and more recently success in awards are clearly included in government/institutional compacts. However, as a bonus to that SoTL work can generate publications and 'category 1 ' research funding.

Brew (2013) reporting on work undertaken at Macquarie University identifies various elements put in place at a structural level which resulted in an improvement of SoTL and subsequent improved outcomes for students. These factors formed a scholarship of teaching index that was used to drive change through rewards based incentives to the faculties and schools to further support SoTL. The index included a points based system to reward qualifications in university teaching, teaching awards at the faculty, university and national levels, publications and presentations on university teaching. While this was seen as the measure of SoTL, the change program was supported via very public and institutional and faculty level events and initiatives. The study found a statistically significant relationship between awards and a change in student experience in relation to their reporting of good teaching, appropriate assessment and generic skills. However, no significance was found against the same measures in relation to publication output. This is likely because awards are based on teaching practice with students where publications may or may not be related to actual practice. This would indicate that to improve student outcomes SoTL incentives should focus on the process related to awards.

Context however is important and the work of Williams, Goulding and Seddon (2013) highlights this point. Their study which examined the culture of scholarly practice in different types of institutions (Vocational Education (VET), mixed sector and higher education) identified a range of additional factors. Language was seen as critical in this study where the concept of research is not as widely embraced in VET as it is seen as removed from practice and largely theoretical. However, the terms 'scholarship' or 'scholarly practice' had far better traction. The idea of quality and how to achieve quality in scholarly practice was also seen as critical in mixed sector institutions suggesting that professional development in this area would be necessary for staff across the institution to gain a clear understanding of what is necessary and to improve the outcomes. 
In their summary, Williams, Goulding et al $(2013$,$) identified four key elements which are at the$ heart of scholarly practice:

Scholarship is a dynamic intersection between knowledge and practice; it is socially constructed and co-produced work; it is a form of learning, where scholars become self-critical inquirers; and it needs to be made public, with scholars accountable to their peers. (p. 18)

These four elements have a clear connection to the value, role and necessity of building a SoTL community as well as identifying some critical elements in doing so. In terms of underlying elements, this work identifies the critical roles of praxis (action, reflection, action) and opening up our teaching practice to peer review.

Praxis or what Williams et al (2013) refer to as action, research/action varies according to sector both in terms of the value placed on it, how it is conducted and the role of theory and view of knowledge generation. It could also be suggested that the concept of praxis in relation to teaching and learning in and of itself is likely to be embraced more readily in some disciplines than others. As such, this is an element that should be addressed across any institution but probably more so in those with VET delivery as there is likely less reflection on actual delivery due to the structural nature of the sector. However, this is also connected to the way that staff build their professional identity - whether it is as a scholar, a teacher or related to a profession/trade. Williams, Goulding et al (2013) reflect that VET trainers are more closely aligned with their industry than those in higher education roles who straddle both their profession and their role as a scholar/academic. Yet, one could question the extent to which academics see themselves as a professional educator as well as a disciplinary expert. This suggests that in higher education, the scholarly/academic elements are largely in place but the idea of being a professional educator may need some further development while in the VET sector the concept of scholarly/academic elements may need enhancement. However, the valuing of the role of professional educator and application of scholarly approaches to one's own practice is the area for attention across both.

The idea of opening up one's work to peer review is common in the research arena via publication. However, it is less accepted and valued in terms of teaching and learning. Teaching in universities has often been seen as a somewhat 'private' practice undertaken by an academic in a discipline and shared only with the class rather than colleagues. While this is a changing to some extent with the introduction of peer review processes being required in some institutions, it is likely to be somewhat challenging and controversial. The idea of publication of one's teaching practice and scholarship is likely to be more acceptable than inclusion of peer review in the classroom but this does not show a link to improved student outcomes (Brew, 2013) which is at the heart of the SoTL approach. As such other methods of peer review of learning and teaching work must be incorporated and supported. Awards assessment are perhaps the highest level of peer review around teaching and as such it is useful to look at some of the data on success rates for institutions to find another perspective on structural factors that may affect learning communities.

\section{Analysis of Awards Success}

In an effort to try to further understand some of the structural drivers of SoTL, an analysis of success rates for Office for Learning and Teaching (OLT) (and formerly the Australian Learning and Teaching Council) citations and awards for teaching and learning for the period of 20092013 was conducted. While it is acknowledged that OLT citations and awards are only one 
measure of SoTL, it can be argued based on the work of Brew (2012) that they are valid as well as being the most outwardly visible and prestigious expressions of the level of SoTL nationally in Australia. Designed to recognise learning and teaching excellence, the criteria on which citations and awards are assessed has at its core the SoTL approach (a reflective and evidence informed approach to the improvement of teaching and student outcomes).

The Australian Office for Learning and Teaching annually provide citations, program awards and teaching excellence awards. As the successful recipients are listed on the OLT website, the data is available publicly. However, there were some minor discrepancies in the data available where the total number and the institutional numbers did not tally. The impact of this on the analysis is limited as it was related to one year where the numbers only varied by two.

Results in each of these categories (citations, program awards and teaching awards) was analysed using basic frequency and cross tabulations in relation to the institution's location (metropolitan/regional), size (Equivalent Full Time Student Load (EFTSL)), predominant mode of delivery (on campus/distance) and student demographic factors (regional/remote NESB, Indigenous, Disability). The institutional data used in the analysis was sourced from the publicly available data on the Department of Industry, Innovation, Science, Research and Tertiary Education website.

What is perhaps most interesting for the purpose of this discussion is that there appeared to be no relationship between location or student demographics and consistent success in receiving Citations for Outstanding Contributions to Student Learning, Awards for programs that Enhance Student Learning or Teaching Excellence Awards. The following table shows the top ten institutions in terms of the total number of awards and citations received in the period from 2009 to 2013.

\begin{tabular}{|l|l|}
\hline University & Total number of citations and awards \\
\hline Queensland University of Technology & 48 \\
\hline Griffith University & 44 \\
\hline University of Western Sydney & 44 \\
\hline Curtin University of Technology & 42 \\
\hline The University of Melbourne & 41 \\
\hline The University of Queensland & 41 \\
\hline Deakin University & 39 \\
\hline Monash University & 37 \\
\hline Flinders University & 36 \\
\hline University of Wollongong & 34 \\
\hline
\end{tabular}

In looking at the data more superficially, four institutions that appear in the top ten rankings (QUT, Griffith, University of Melbourne and Monash) and all are large institutions, with a predominantly on campus student cohort and teaching more than $80 \%$ of students in internal mode. While the size and the mode do not by default lead to success in teaching awards one might surmise that larger institutions are more likely to be able to allocate resources to support 
the development of SoTL than smaller institutions. In terms of mode, work needs to be done to find ways to support and demonstrate a SoTL approach in diverse modes of engagement. While distance education has been in place for a very long time, the newer form of online learning is still in relative infancy in terms of pedagogical underpinnings and clear identification of what constitutes good teaching practice. It is also of course possible that mode is not a key factor but rather than the size plays a larger role.

Regional institutions (with $50 \%$ or more enrolled students classified as regional or remote) perform slightly better in the program and teaching excellence categories, with two in each of the top 10 lists (James Cook and Tasmania) whereas only one appears in the top 10 citations list (James Cook), and none in the overall list as presented above. There are likely to be a range of factors that contribute to this result but one possible scenario is the fact that regional universities tend to experience a higher rate of staff turnover making it more difficult to demonstrate a sustained improvement to teaching over a period of time on an individual basis (a key criteria for citations and awards).

It is also interesting to note that there are no dual sector institutions on the top 10 lists. While there are only a few of these nationally, it may also be connected to the cultural elements and complexity around the development of SoTL in such institutions as related to the work of Williams et al (2013).

Additionally, it should also be noted that despite Macquarie University putting in place a systematic approach to developing SoTL, they still do not appear in the top 10 list above. This might suggest that there are other factors in play beyond the structural elements.

While we can only largely speculate on the drivers behind these results in relation to SoTL, there are some trends which are worthy of consideration within a framework to increase the likelihood of success. These include improving and disseminating a SoTL approach for external/online education, identifying key infrastructure that is offered by larger institutions, putting in place strategies to ameliorate the barriers presented in regional areas.

\section{Framework for a SoTL community}

Reflecting on both the literature and the characteristics of successful institutions, we can draw together the range of factors that contribute to building a SoTL community. It must be acknowledged that the overall direction must be set by the executive of the university and that all elements must align consistently in order to support the first element: explicitly valuing SoTL. If there are mixed messages or a lack of support for various elements at a school or faculty level then the intention will be undermined at least to some extent. Each level of management must support the overall value of SoTL and demonstrate this through actions.

The following table highlights the key factors found through the investigation and also provides some suggestions of how these elements might be addressed. 


\begin{tabular}{|c|c|}
\hline Key element & How? \\
\hline $\begin{array}{l}\text { Explicitly valuing SoTL } \\
\text { as important and equal } \\
\text { to research across the } \\
\text { institution }\end{array}$ & $\begin{array}{l}\text { - Setting the agenda and ensuring all areas of the university } \\
\text { are consistent in valuing SoTL } \\
\text { - Explicit in the strategic plan } \\
\text { - Ensuring resources are in place to support SoTL } \\
\text { - EBA that equally values, counts valid SoTL outputs (e.g. } \\
\text { category } 1 \text { funding, publication) } \\
\text { - Promotion processes and outcomes that demonstrate the } \\
\text { equal value SoTL } \\
\text { - Ensuring staff have qualifications in university teaching } \\
\text { - T \& L awards and grants program in place } \\
\text { - Rewarding SoTL at various levels (e.g. incentives for } \\
\text { - engagement and success in SoTL) } \\
\text { Employment framework that values 'professional educator' } \\
\text { role equally to research }\end{array}$ \\
\hline $\begin{array}{l}\text { Resourcing to support } \\
\text { SoTL }\end{array}$ & $\begin{array}{l}\text { - Workload allocations that allow time for SoTL } \\
\text { - Funding for small T \& L Grants and Awards } \\
\text { - Funding for and support for qualifications in teaching that } \\
\text { embed the key SoTL elements } \\
\text { - Funding for support services to assist with award and } \\
\text { grant applications }\end{array}$ \\
\hline Networks & $\begin{array}{l}\text { Building networks to strengthen SoTL across the } \\
\text { institution; between sectors, across faculties and schools } \\
\text { - Provide opportunities and strongly encourage peer review } \\
\text { of teaching and sharing of teaching practice development/ } \\
\text { innovations }\end{array}$ \\
\hline $\begin{array}{l}\text { Capacity building in } \\
\text { SoTL }\end{array}$ & $\begin{array}{l}\text { - Having an institutional SoTL plan to draw together the } \\
\text { elements } \\
\text { - Professional development for understanding SoTL at } \\
\text { various stages (including induction) } \\
\text { - Large and small activities to demonstrate importance and } \\
\text { engage diverse academics } \\
\text { - Openness to reflective practice } \\
\text { - Peer review of SoTL components }\end{array}$ \\
\hline $\begin{array}{l}\text { Availability of SoTL } \\
\text { tools }\end{array}$ & $\begin{array}{l}\text { - Centrally held data available for use } \\
\text { - Systems in place to easily collect data on L \& T (e.g. } \\
\text { analytics; data warehouse) } \\
\text { - Streamlined ethics process for SoTL work } \\
\text { - Professional development tools readily available }\end{array}$ \\
\hline $\begin{array}{l}\text { Embedding of SoTL in } \\
\text { curriculum review and } \\
\text { development }\end{array}$ & $\begin{array}{l}\text { - Curriculum review processes required on a regular basis } \\
\text { - SoTL aligned with and embedded in curriculum } \\
\text { development and review processes }\end{array}$ \\
\hline Language & $\begin{array}{l}\text { - Using appropriate language that engages staff across the } \\
\text { institution } \\
\text { - Using language that demonstrates the value of SoTL }\end{array}$ \\
\hline
\end{tabular}


These appear to be the basic elements, however each institution will need to reflect on its own characteristics in order to put in place additional elements or contextualise elements. For example an institution that has a high rate of external delivery would need to be explicit about capacity building in relation to pedagogical approach for an online mode.

Universities with a higher rate of staff turnover would need to bolster networks to ameliorate the impact of this on the development of SoTL, perhaps placing more focus on team teaching leading to team citations or program awards. Dual sector institutions will need to carefully consider the language used and the translation of the SoTL concepts into an appropriate framework. The professional development in such institutions would need a greater focus on the SoTL process and how it can be achieved.

If we return to the concept of the learning community as defined by Plant (1974), the elements of the framework must come together to create, support and build a relatively stable and permanent structure. Rather than creating groups (which are largely homogenous, specialised and transitory) that are focused on SoTL we need to focus our attention on moving to the level of community (pluralistic and heterogeneous). In that sense, structure is critical to the endeavour but the operationalization of those elements is also vital. For example, networks should be built to cross disciplinary boundaries to bring in new ideas and share them more broadly. The discussion also needs to occur at a broader level than communities of practice which while useful remain largely localised.

In working on a range of projects related to SoTL (e.g., Southwell, West \& Scoufis, 2008; Vilkinas \& West, 2010; South Australia/Northern Territory Promoting Excellence Network, 2013,2014 ) it has become apparent that while there is interest across institutions, it remains fairly localised and relatively small. Even for many of those engaged in the concept much work is needed in setting people on a path to SoTL beginning with what it is and how it can be carried out. However, as the key elements of the framework align, there is more likelihood that a tipping point can be reached.

Additionally, while the government is focused on scholarship as the "dissemination' of knowledge and a "commitment to the development of teaching practice" to distinguish it from research as 'the creation of new knowledge' (Probert, 2014), this does not appear to be sufficient. This takes a fairly limited and low level view of SoTL which is unhelpful in making improvements to student outcomes. For example, with the increasing reliance on online education and the changes that this is driving in education, it is vital that research and publication is undertaken to build a publicly recognised and evidence based approach to online teaching and learning. To be relevant and effective across the sector, the work needs to be undertaken on a much broader scale than those who teach (and research) education in the more traditional sense. In this context it is SoTL work and should be recognised as such. This will not only contribute to the knowledge base but also provide some benchmarks for effective evaluation of citations and awards that are related to the online environment.

\section{Conclusion}

The value of building a SoTL community is multifaceted. As demonstrated earlier a SoTL approach assists in improving the student experience of teaching. From an institutional point of view this is of great benefit through improved retention rates, student satisfaction outcomes, success in awards and grants, all of which are embedded in compacts with the government.

The inclusion of higher level elements along with a consistency of approach is likely to engage staff in the pursuit of SoTL to build a learning community. Key drivers for staff are likely to be 
around promotion, improvement of practice, publicly recognised rewards (publication, grants and awards) as well as the ongoing development of scholarly identity. Of course this will vary with individuals but the breadth of the drivers means that it is increasingly likely that the 'tipping point' will be reached and a culture of SoTL will become more predominant.

\section{References}

Australian Learning and Teaching Council. (2010). Australian Learning and Teaching Council Awards Scheme Report 2009. Retrieved from http://www.olt.gov.au/system/files/2009\%20Awards\%20 Scheme\%20Report_0.pdf.

Australian Learning and Teaching Council. (2011). Australian Learning and Teaching Council Awards Scheme Report 2010. Retrieved from http://www.olt.gov.au/system/files/2010\%20Awards\%20 Scheme\%20Report\%20v1.0.pdf.

Boyer, E. L. (1990). Scholarship reconsidered: Priorities of the professoriate. Princeton, N.J: The Carnegie Foundation for the Advancement of Teaching.

Brew, A. (2012). Developing the Scholarship of Teaching and Learning at an Institutional Level. International Society for the Scholarship of Teaching and Learning Conference, Hamilton, Ontario, 24-27th October.

Department of Industry, Innovation, Science, Research and Tertiary Education. (2013). uCube, Higher Education Statistics. Retrieved from http://www.highereducationstatistics.deewr.gov.au.

DuFour, R. (2004) What Is a 'Professional Learning Community'? Educational Leadership, 61(8), 6-11.

Hutchings, P., Borin, P, Keesing-Styles, L., Martin, L., Michael, R., Scharff, L. Simkins, S. \& Ismail, A. (2013). The Scholarship of Teaching and Learning in an Age of Accountability: Building Bridges. Teaching and Learning Inquiry: The ISSOTL Journal, 1(2) 35-47. Retrieved from http://www.jstor. org/stable/10.2979/teachlearninqu.1.2.35.

Lave, J., \& Wenger, E. (1991). Situated learning: Legitimate peripheral participation. Cambridge, MA: Cambridge University Press.

Major, C.H. \& Palmer, B. (2006) Researching teaching and learning: The transformation of faculty pedagogical content knowledge. Higher Education: The International Journal of Higher Education Research, 51, 619-647. DOI: 10.1007/s10734-004-1391-2

Office for Learning and Teaching. (2011). Office for Learning and Teaching Citations Assessment Report 2011. Retrieved from http://www.olt.gov.au/system/files/2011\%20AAUT\%20Citations\%20 program\%20assessment\%20report_0.pdf.

Office for Learning and Teaching. (2012). Office for Learning and Teaching Citation Program: Assessment Report, 2012. Retrieved from http://www.olt.gov.au/system/files/2012CitationsAssessmentReport. pdf.

Plant, R. (1974). Community ideology. London: Routledge \& Kegan Paul.

Probert, B. (2014). Why scholarship matters in higher education. Sydney: Office for Learning and Teaching.

South Australia and Northern Territory Promoting Excellence Network. (2014). SANTPEN online resources. Retrieved from http://santpen.weebly.com/.

Southwell, D., West, D. \& Scoufis, M. (2008). Caught between a rock and several hard places: Cultivating the role of the Associate Dean and the Course Coordinator. Strawberry Hills, NSW: Carrick Institute. 
Van Krieken, R., Habibis, D., Smith, P., Hutchins, B., Martin, G. \& Maton, K. (2010). Sociology (4th Edition). Frenchs Forest, NSW: Pearson.

Vilkinas, T. \& West, D. (2010). Building Academic Leadership Capability. Australian Learning and Teaching Council, Strawberry Hills, NSW.

Wenger, E. (2006). Communities of Practice: a brief introduction. Available online at: http://wengertrayner.com/introduction-to-communities-of-practice/ Accessed 05 January 2016.

Wenger, E. (1999). Communities of Practice: Learning, Meaning, and Identity. Cambridge University Press, Cambridge, UK.

Williams, A., Verwoord, R., Beery, T., Dalton, H., McKinnon, J., Strickland, K., Pace, J. \& Poole, G. (2013). The Power of Social Networks: A Model for Weaving the Scholarship of Teaching and Learning into Institutional Culture. Teaching and Learning Inquiry: The ISSOTL Journal, 1(2) 49-62. Retrieved from http://www.jstor.org/stable/10.2979/teachlearninqu.1.2.49.

Williams, M., Goulding, F. \& Seddon, T. (2013). Towards a culture of scholarly practices in mixed-sector institutions. Adelaide: NCVER. 